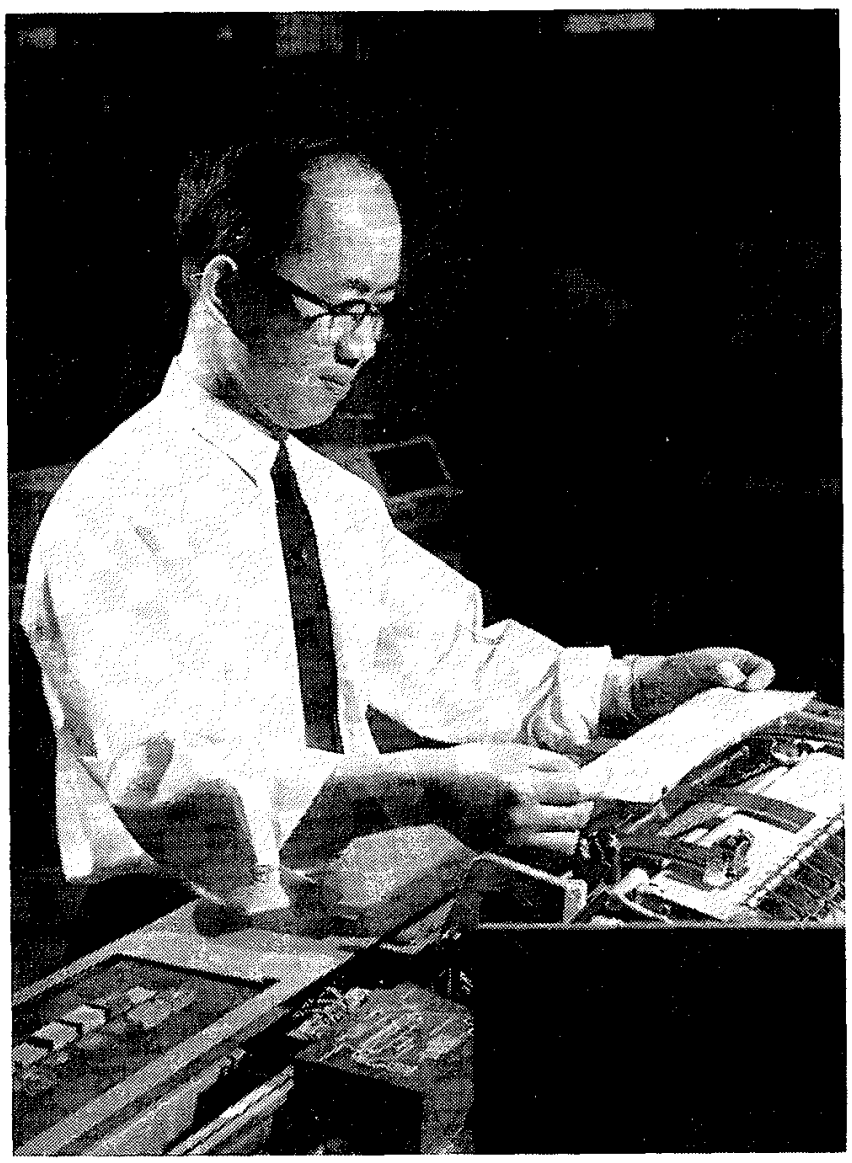

An IBM 1440 computor is used in headquorters of the Vancouver Forest District to record thousands of focts and figures relating to timber scaling and billing in the district. Electronic brain was instalied about four years ago to replace comparatively primitive methods of the past, and is the only computer doing such Forest Service work in the province. Checking complicated mass of figures is Gilbert Chan, senior computer operator. (Forest Service photo)

menced adoption of timber measurement in terms of cubic feet. This form of measure is in effect today in the scaling of all timber taken from Crown (publicly owned) lands.

Forest Service officials are the first to admit that even the cubic content measurement is not the perfect answer - especially in terms of the timber's quality and density. But those two major factors can be and are cared for, to a large degree, through careful grading.

The British Columbia Cubic Scale Rule provides uniform results, no matter how a tree may be cut up; and it can be applied anywhere the diameter and length of a log can be measured - in the woods, loaded, or in water.

All commercially harvested timber in British Columbia is subjected to such measurement - or scaling - by government licenced personnel.

Responsible for this task is the B.C. Forest Service, through its official scaling staff. Each of the province's five Forest Districts has its own scaling unit.

Most active of the five is the Vancouver Forest District, which covers approximately 34,880 square miles (including all of Vancouver Island), with headquarters in Vancouver.

It's big business. The district has about 170 scalers, plus a small number of apprentices receiving on-the-job training. They work under the jurisdiction of H. L. (Larry) Coles, Superintendent of Scaling, who has held the position for the past 10 years.

In 1967, the last year for which an official figure is available, these men scaled approximately 1,000,000,000 cubic feet of timber, nearly 58 per cent of the provincial cut.

The scaler's life is an interesting one. It can also be dangerous. He travels a lot, and spends all of his working time outdoors. As a student he will earn about $\$ 11$ a day. Senior personnel draw up to $\$ 830$ per month.

Full-fledged scalers in the government service are expected to come within three percent of the grand total in their calculations in both footage and value.

Industry foots the bill for scaling costs. What happens if any interested party in a timber transaction is not satisfied with the tally of the government man?

"He can call for a re-scale," replies Superintendent Coles. "The Forest Service will then send two or more senior scalers for a check. If the re-check tally is within three percent of the original figure the inquiring party pays for the re-scale. Otherwise, there is no additional charge."

Like practically all other aspects of the Forest Service, scaling practices are under constant review. Undoubtedly - as time goes on - new forms of log measurement will be introduced. But it appears the surefooted scaler with his hooked stick and caulked boots will be on the forest scene for quite some time yet.

Public Information Division B.C. Forest Service, Victoria, B.C.

\title{
Can You Help?
}

We have been unable to contact the following members and would appreciate hearing from anyone who knows of their present whereabouts. The Section indicates the area in which they were last heard from.

M. A. Paget

Cariboo
D. W. Algar

R. G. Christie

R. W. Walker

R. Jansen

P. M. Paul

C. K. Sumi
Champlain

Okanagan

Maritimes

Cariboo

Maritimes

Lake of the Woods 